\title{
Myocardial Infarction-Prone Watanabe Heritable Hyperlipidemic Rabbits with Mesenteric Fat Accumulation Are a Novel Animal Model for Metabolic Syndrome
}

\author{
Masashi Shiomi $^{\mathrm{a}, \mathrm{b}}$ Tsutomu Kobayashi ${ }^{\mathrm{a}} \quad$ Nobue Kuniyoshi $^{\mathrm{a}}$ Satoshi Yamada ${ }^{\mathrm{a}}$ \\ Takashi lto ${ }^{a}$

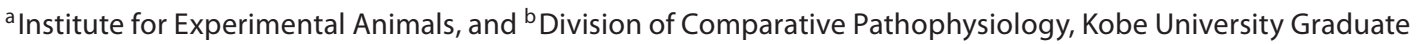 \\ School of Medicine, Kobe, Japan
}

\section{Key Words}

Atherosclerosis $\cdot$ Insulin resistance $\cdot$ Mesenteric fat accumulation $\cdot$ Metabolic syndrome $\cdot$ Myocardial infarction-prone Watanabe heritable hyperlipidemic rabbits

\begin{abstract}
Objectives: To examine whether the myocardial infarctionprone Watanabe heritable hyperlipidemic (WHHLMI) rabbit with visceral fat accumulation is a new animal model for human metabolic syndrome, we examined the relationship between mesenteric fat accumulation and insulin resistance, hyperlipidemia and atherosclerosis. Methods: Glucose tolerance tests were performed using adult (11- to 15-month-old) and middle-aged (17- to 21-month-old) WHHLMI rabbits fed standard chow restrictedly. In addition, lipoprotein lipid levels, serum C-reactive protein (CRP) levels, mesenteric fat weight and physical and physiological parameters were measured. Mesenteric fat was stained immunohistochemically. Results: The mesenteric adipose tissue was positive for monoclonal antibodies against macrophages, C-reactive protein and monocyte chemoattractant protein. In adult rabbits, mesenteric fat correlated to aortic lesion area, insulin resistance, fasting immunoreactive insulin, serum CRP,
\end{abstract}

abdominal circumference and body weight. In middle-aged rabbits, mesenteric fat correlated to lipoprotein lipid levels in addition to the parameters showing a significant correlation in adult rabbits, excluding aortic lesion area. Conclusions: The WHHLMI rabbit with visceral fat accumulation is a new animal model for metabolic syndrome.

$$
\text { Copyright } \odot 2012 \text { S. Karger AG, Basel }
$$

\section{Introduction}

Raised serum cholesterol levels are considered a major risk factor for atherosclerosis. However, hypocholesterolemic treatment is effective at preventing coronary events in less than $50 \%$ of patients [1]. Therefore, lipid abnormalities can only partly explain the prevalence of the development of coronary heart disease, and the control of factors other than serum cholesterol levels is important to lower the prevalence of heart disease. Metabolic syndrome is associated with an increased risk of both diabetes and cardiovascular disease [2] and has a very high prevalence (24\% in the USA and between 24.6 and $30.9 \%$ in Europe) [3]. According to the International Diabetes Federation, metabolic syndrome is a disease cluster involving the accumulation of mesenteric fat (visceral fat)

\section{KARGER}

Fax +4161306 1234 E-Mail karger@karger.ch www.karger.com

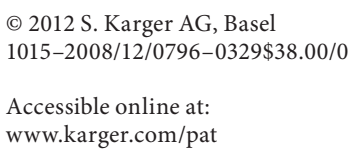

Masashi Shiomi

Institute for Experimental Animals and Division of Comparative Pathophysiology

Kobe University Graduate School of Medicine

7-5-1, Kusunoki-cho, Chuo-ku, Kobe 650-0017 (Japan)

Tel. +81 78382 6900, E-Mail ieakusm@med.kobe-u.ac.jp 
accompanying any two of the following: insulin resistance (or mild hyperglycemia), hypertriglyceridemia, low high-density lipoprotein (HDL) cholesterol levels and raised blood pressure [4].

Studies using genetically modified mice and spontaneous mutant mice have contributed to the finding of adipocytokines, clarifying their role [5], and the molecular mechanisms underlying the development of metabolic syndrome [6]. However, the lipoprotein metabolism in rodents differs markedly from that in humans [7], and there are no rodent models for metabolic syndrome with atherosclerosis, except a few mouse strains with slight atherosclerotic lesions $[8,9]$. Recently, a swine model for metabolic syndrome was established using an atherogenic diet [10]. This model is useful for stent experiments, but the correlation between mesenteric fat accumulation and atherosclerosis is unclear. However, in rabbits, lipoprotein metabolism resembles that in humans $[11,12]$. The postprandial hyperlipidemic rabbit shows intraperitoneal fat accumulation, insulin resistance and postprandial hypertriglyceridemia [13], mimicking human metabolic syndrome, although no atherosclerotic lesions develop. Recently, Waqar et al. [14] reported that a high-fat diet induced metabolic syndrome and atherosclerosis in rabbits. They clearly demonstrated that their model is similar to human metabolic syndrome. However, they did not analyze the influence of mesenteric fat accumulation or insulin resistance on plasma lipid levels or the degree of atherosclerosis.

At Kobe University, we developed the Watanabe heritable hyperlipidemic (WHHL) rabbit, an animal model of familial hypercholesterolemia [15]. WHHL rabbits show hypercholesterolemia due to a genetic defect of low-density lipoprotein receptors and spontaneous atherosclerosis [12]. We have also developed a myocardial infarctionprone strain (WHHLMI rabbits) by selective breeding of WHHL rabbits [16]. Some WHHL rabbits showed intraperitoneal fat accumulation and insulin resistance, and these findings were improved by a thiazolidinedione derivative, a peroxisome proliferator-activated receptor- $\gamma$ agonist [17, 18], which is an insulin action enhancer. These studies suggest WHHL or WHHLMI rabbits with intraperitoneal fat accumulation to be a good animal model for examining the relationship between metabolic syndrome and the development of atherosclerosis. In the present study, we examined the relationship between mesenteric fat accumulation and insulin resistance, hyperlipidemia and atherosclerosis, to examine whether the WHHLMI rabbit with mesenteric fat accumulation is a new animal model for human metabolic syndrome.

\section{Materials and Methods}

\section{Animal Care and Use}

We used 46 WHHLMI rabbits aged 11-15 months (adult) and 52 WHHLMI rabbits aged 17-21 months (middle-aged), as well as 10 adult Japanese white rabbits as a normal control. The WHHLMI rabbits were bred at the Kobe University Graduate School of Medicine. The Japanese white rabbits were obtained from Kitayama Labs, Co. Ltd. (Ina, Japan). The rabbits resided individually in metal cages (550 mm wide, $600 \mathrm{~mm}$ deep and 450 $\mathrm{mm}$ high) with a flat metal floor and consumed standard rabbit chow (LRC4, Oriental Yeast Co., Ltd., Tokyo, Japan) at 120 g/day and water ad libitum. The animal rooms were maintained under constant temperature $\left(22 \pm 2^{\circ} \mathrm{C}\right)$, relative humidity $(50-60 \%)$, ventilation rate $(15$ cycles/h) and lighting cycle $(12 \mathrm{~h} \mathrm{light} / 12 \mathrm{~h}$ dark). This study was approved by the Institutional Animal Care and Use Committee (approval numbers: P080111R, P091011R), and animal experiments were conducted in accordance with the Regulations for Animal Experimentation of Kobe University, the Act on Welfare and Management of Animals (Law No. 105; 1973, revised in 2006), Standards Relating to the Care and Management of Laboratory Animals and Relief of Pain (Notification No. 88, 2006) and Fundamental Guidelines for the Proper Conduct of Animal Experiments and Related Activities in Academic Research Institutions under the Justification of the Ministry of Education, Culture, Sports, Science and Technology (Notice No. 71, 2006).

\section{Intravenous and Oral Glucose Tolerance Tests}

The intravenous glucose tolerance test (IVGTT) Swas carried out according to methods described previously [17, 18]. After 16 hours' fasting, rabbits were injected with a glucose solution $(0.6$ $\mathrm{g} / \mathrm{kg}$ body weight) into a marginal ear vein. Blood samples were collected through ear veins $0,5,10,20,30,60$ and 120 min after the glucose was administered. The oral glucose tolerance test (OGTT) was performed as described previously [13]. After 16 hours' fasting, rabbits were administered a glucose solution (1.5 $\mathrm{g} / \mathrm{kg}$ body weight) orally. Blood samples were collected through marginal ear veins $0,15,30,45,60,90,120,180$ and 240 min after the glucose administration. Blood sugar and immunoreactive insulin (IRI) concentrations were assayed. Using fasting blood sugar and IRI levels, homeostasis model assessment-insulin resistance (HOMA-IR) [19] and the Matsuda insulin sensitivity index (ISI) [20], Matsuda and DeFronzo [20] demonstrated that the Matsuda-ISI in the OGTT closely reflects whole-body insulin sensitivity.

Measurements of Body Size and Blood Pressure

Blood pressure in conscious rabbits was monitored directly at the ear central artery. An intravenous infusion catheter $(18 \mathrm{G} \times$ 2 inches, SR-FF1851, Termo, Japan) was inserted into the ear artery. A transducer (DTX Plus DT-4812, Becton Dickinson Inc., N.J., USA) was connected to the catheter via pressure tubing (TPT-12, PT-06 or PT-60, Becton Dickinson). Recordings were made with PowerLab 8/SP (ADInstruments). After euthanasia of the rabbits by intravenous injection of pentobarbital $(30 \mathrm{mg} / \mathrm{kg})$, the abdominal circumference at the lowest part of the costal bone and length from shoulder to buttocks were measured. Mesenteric fat, axillary fat, inguinal fat, the aorta and the heart were excised. 
Table 1. Baseline data of adult (10- to 15-month-old) and middle-aged (17- to 21-month-old) WHHLMI rabbits

\begin{tabular}{|c|c|c|c|}
\hline & \multirow{2}{*}{$\begin{array}{l}\text { Adult Japanese } \\
\text { white rabbits }\end{array}$} & \multicolumn{2}{|l|}{ WHHLMI rabbits } \\
\hline & & adult & middle-aged \\
\hline Body weight, kg & $3.58 \pm 0.10(10)$ & $3.33 \pm 0.04(46)$ & $3.53 \pm 0.05(52)$ \\
\hline Abdominal circumference, $\mathrm{cm}$ & $38.3 \pm 0.9(10)$ & $38.3 \pm 0.40(46)$ & $39.4 \pm 0.42(52)$ \\
\hline $\mathrm{BMI}, \mathrm{kg} / \mathrm{cm} / \mathrm{cm} \times 10,000$ & $25.5 \pm 1.4(10)$ & $25.4 \pm 0.54(40)$ & $26.2 \pm 0.48(49)$ \\
\hline \multicolumn{4}{|l|}{ Fat accumulation, $g$} \\
\hline Mesenteric fat & $48.1 \pm 9.8(9)$ & $69.8 \pm 4.6(46)$ & $92.2 \pm 6.5(52)^{\mathrm{a}, \mathrm{b}}$ \\
\hline Axillary fat & $19.0 \pm 3.3(9)$ & $17.6 \pm 1.6(37)$ & $17.3 \pm 1.3(50)$ \\
\hline Inguinal fat & $22.0 \pm 2.6(9)$ & $27.3 \pm 1.8(37)$ & $33.0 \pm 2.4(50)^{\mathrm{a}}$ \\
\hline Fasting blood sugar, mg/dl & $129 \pm 2.3(10)$ & $130 \pm 2.3(35)$ & $117 \pm 1.8(37)^{\mathrm{a}, \mathrm{b}}$ \\
\hline Fasting IRI, ng/ml & $0.82 \pm 0.09(10)$ & $1.29 \pm 0.28(25)$ & $1.60 \pm 0.34(34)$ \\
\hline HOMA-IR & $6.12 \pm 0.72(10)$ & $10.2 \pm 2.4(25)$ & $11.2 \pm 2.6(34)$ \\
\hline Matsuda-ISI on the IVGTT & $2.89 \pm 0.41(10)$ & $3.08 \pm 0.37(21)$ & $3.66 \pm 0.75(17)$ \\
\hline Matsuda-ISI on the OGTT & $2.73 \pm 0.32(10)$ & $3.56 \pm 0.46(21)$ & $3.28 \pm 0.57(18)$ \\
\hline Serum total cholesterol, mg/dl & $15.0 \pm 1.8(8)$ & $820 \pm 39(41)^{\mathrm{a}}$ & $761 \pm 27(42)^{\mathrm{a}}$ \\
\hline VLDL cholesterol, mg/dl & $3.5 \pm 1.8(8)$ & $88.7 \pm 10.5(16)^{\mathrm{a}}$ & $107 \pm 17(17)^{\mathrm{a}}$ \\
\hline LDL cholesterol, mg/dl & $2.5 \pm 0.4(8)$ & $773 \pm 34(16)^{\mathrm{a}}$ & $730 \pm 35(17)^{\mathrm{a}}$ \\
\hline HDL cholesterol, mg/dl & $9.0 \pm 1.5(8)$ & $13.7 \pm 1.1(16)$ & $13.7 \pm 1.1(17)$ \\
\hline Serum triglyceride level, mg/dl & $44.9 \pm 6.8(8)$ & $331 \pm 34(40)^{\mathrm{a}}$ & $323 \pm 32(41)^{\mathrm{a}}$ \\
\hline VLDL triglyceride, $\mathrm{mg} / \mathrm{dl}$ & $21.5 \pm 5.1(8)$ & $47.1 \pm 5.2(16)^{\mathrm{a}}$ & $67.3 \pm 13.7(17)^{\mathrm{a}}$ \\
\hline LDL triglyceride, mg/dl & $4.5 \pm 1.9(8)$ & $196 \pm 13(16)^{\mathrm{a}}$ & $230 \pm 19(17)^{\mathrm{a}}$ \\
\hline HDL triglyceride, $\mathrm{mg} / \mathrm{dl}$ & $24.1 \pm 2.3(8)$ & $18.6 \pm 2.1(16)$ & $17.9 \pm 1.2(17)$ \\
\hline Whole triglyceride/HDL cholesterol ratio & $11.3 \pm 5.3(8)$ & $18.1 \pm 1.8(16)$ & $27.1 \pm 4.6(17)^{\mathrm{a}}$ \\
\hline Systolic blood pressure, $\mathrm{cm} \mathrm{Hg}$ & $116 \pm 6.5(5)$ & $122 \pm 3.1(16)$ & $121 \pm 4.3(15)$ \\
\hline Diastolic blood pressure, $\mathrm{cm} \mathrm{Hg}$ & $87.5 \pm 2.9(5)$ & $85.0 \pm 1.8(16)$ & $79.0 \pm 2.3(15)$ \\
\hline Surface lesion area of aorta, $\%$ & 0 & $75.1 \pm 3.4(46)^{\mathrm{a}}$ & $88.2 \pm 0.8(52)^{\mathrm{a}, \mathrm{b}}$ \\
\hline Serum CRP, $\mu \mathrm{g} / \mathrm{ml}$ & $7.6 \pm 0.7(7)$ & $34.7 \pm 5.9(20)$ & $86.2 \pm 40(17)$ \\
\hline
\end{tabular}

Values in parentheses represent the number of rabbits analyzed. Data are presented as means \pm SEM. Statistical analyses were carried out with Scheffe's multiple comparison test.

${ }^{\mathrm{a}} \mathrm{p}<0.05$ versus Japanese white rabbits; ${ }^{\mathrm{b}} \mathrm{p}<0.005$ versus adult WHHLMI rabbits. BMI = Body mass index [body weight/(length between shoulder and buttocks) $\left.{ }^{2} \times 10,000\right]$; IVGTT $=$ intravenous glucose tolerance test; OGTT = oral glucose tolerance test; $\mathrm{VLDL}=$ very low-density lipoprotein; $\mathrm{LDL}=$ low-density lipoprotein; $\mathrm{HDL}=$ high-density lipoprotein; $\mathrm{CRP}=\mathrm{C}$-reactive protein.

\section{Preparation of Histological Sections}

After the adipose tissue and heart were weighed, they were fixed with a $10 \%$ buffered formalin solution and embedded in paraffin. Each section was sliced serially to a thickness of $4 \mu \mathrm{m}$. Sections were stained immunohistochemically with monoclonal antibodies specific for rabbit monocytes/macrophages (RAM-11, Dako A/S, Glostrup, Denmark), monocyte chemoattractant protein-1 (MCP-1; Dako A/S) and C-reactive protein (CRP; Dako $\mathrm{A} / \mathrm{S}$ ). Immunohistochemical staining was carried out using a Dako Envision+ kit according to the manufacturer's instructions, accompanied by hematoxylin counterstaining.

\section{Evaluation of Atherosclerotic Lesions of the Aorta}

All parameters for atherosclerotic lesions were measured by computer-assisted color image analysis (Image-Pro Plus, version 4.5, Media Cybernetics Inc., Silver Spring, Md., USA). Aortic atherosclerosis was evaluated using the percentage surface area of lesions on the whole aorta (surface area of lesion/surface area of the whole intima $\times 100)[21]$.
Preparation of Plasma Lipoproteins and Biochemical Analyses Lipoproteins were fractionated by ultracentrifugation (very low-density lipoprotein (VLDL), density $<1.006 \mathrm{~g} / \mathrm{ml}$; low-density lipoprotein (LDL), $1.006 \mathrm{~g} / \mathrm{ml}<$ density $<1.063 \mathrm{mg} / \mathrm{dl}$; HDL, density $>1.063 \mathrm{~g} / \mathrm{ml}$ ) [22]. Total cholesterol and triglyceride levels were assayed by enzymatic methods. Blood sugar levels were assayed with Antsense III (Horiba Ltd., Kyoto, Japan). Serum insulin levels and CRP levels were assayed with ELISA kits (Rat Insulin ELISA kit and Rabbit CRP ELISA kit, Shibayagi Co., Ltd., Shibukawa, Japan).

\section{Statistical Analyses}

Data are presented as means \pm SEM. Statistical analyses were carried out for mean values with Student's t test or Welch's t test, or for the mean values among multiple groups with Scheffe's multiple comparison test, and for frequency with a $\chi^{2}$ test. Correlation analyses were carried out with Pearson's correlation test. A value of $\mathrm{p}<0.05$ was considered statistically significant. 
Table 2. Correlation between accumulation of fat and physical or physiological parameters of adult (11- to 15-month-old) and middleaged (17- to 21-month-old) WHHLMI rabbits

\begin{tabular}{|c|c|c|c|c|c|c|c|c|c|c|c|c|}
\hline & \multicolumn{6}{|c|}{ Adult rabbits } & \multicolumn{6}{|c|}{ Middle-aged rabbits } \\
\hline & \multicolumn{3}{|c|}{ mesenteric fat } & \multicolumn{3}{|c|}{ subcutaneous fat } & \multicolumn{3}{|c|}{ mesenteric fat } & \multicolumn{3}{|c|}{ subcutaneous fat } \\
\hline & $\mathrm{n}$ & $\mathrm{r}$ & $\mathrm{p}$ value & $\mathrm{n}$ & $\mathrm{r}$ & $\mathrm{p}$ value & $\mathrm{n}$ & $\mathrm{r}$ & $\mathrm{p}$ value & $\mathrm{n}$ & $\mathrm{r}$ & $\mathrm{p}$ value \\
\hline Age & 46 & 0.013 & n.s. & 37 & 0.373 & 0.014 & 52 & -0.078 & n.s. & 50 & -0.005 & n.s. \\
\hline Body weight & 46 & 0.349 & 0.002 & 37 & 0.405 & 0.007 & 52 & 0.682 & $<0.001$ & 50 & 0.481 & $<0.001$ \\
\hline Abdominal circumference & 46 & 0.327 & 0.027 & 37 & 0.319 & 0.037 & 52 & 0.646 & $<0.001$ & 50 & 0.440 & 0.001 \\
\hline BMI & 46 & 0.112 & n.s. & 34 & 0.306 & 0.055 & 50 & 0.541 & $<0.001$ & 49 & 0.240 & n.s. \\
\hline Subcutaneous fat & 37 & 0.363 & 0.017 & & & & 50 & 0.649 & $<0.001$ & & & \\
\hline \multicolumn{13}{|l|}{ Blood pressure } \\
\hline Systolic & 16 & -0.200 & n.s. & 15 & 0.129 & n.s. & 15 & 0.343 & n.s. & 13 & 0.083 & n.s. \\
\hline Diastolic & 16 & -0.310 & n.s. & 15 & -0.021 & n.s. & 15 & 0.257 & n.s. & 13 & 0.245 & n.s. \\
\hline Average & 16 & 0.319 & n.s. & 15 & -0.042 & n.s. & 15 & 0.268 & n.s. & 13 & 0.176 & n.s. \\
\hline $\begin{array}{l}\text { Percentage surface lesion } \\
\text { area of aorta }\end{array}$ & 46 & 0.331 & 0.025 & 37 & 0.043 & n.s. & 52 & -0.085 & n.s. & 50 & -0.176 & n.s. \\
\hline
\end{tabular}

Subcutaneous fat was measured as the sum of inguinal fat and axillary fat. Correlation analyses were carried out with Pearson's correlation test. A value of $\mathrm{p}<0.05$ was considered statistically significant. BMI = Body mass index; n.s. $=$ not significant.

\section{Results}

\section{Baseline Data of WHHLMI Rabbits}

There were no significant differences in baseline data, except for serum or lipoprotein lipid levels and atherosclerotic lesions, between adult WHHLMI rabbits and Japanese white rabbits (table 1). In middle-aged WHHLMI rabbits, the accumulation of fat in the mesentery and inguinal region was increased and blood sugar levels were lowered compared with values in adult WHHLMI rabbits and Japanese white rabbits.

\section{Accumulation of Mesenteric Fat in WHHLMI Rabbits}

Figure 1a and $\mathrm{b}$ shows the accumulation of intraperitoneal fat in middle-aged WHHLMI rabbits compared to Japanese white rabbits (fig. 1c, d). In the mesenteric fat of WHHLMI rabbits, RAM-11-positive cells (monocytes/ macrophages) were observed in swollen adipocytes with lipid (fig. 1e) and were positive for MCP-1 (fig. 1f) and CRP (fig. 1g, h).

\section{Glucose Tolerance Tests}

Figure 2 shows results of glucose tolerance tests in adult rabbits. Changes in blood sugar levels were similar among the three groups. However, after glucose administration, serum IRI levels were markedly higher in WHHLMI rabbits with high fasting IRI levels than in WHHLMI and Japanese white rabbits with normal fast- ing IRI levels. As a result, the HOMA-IR value was significantly higher and the Matsuda-ISI in the OGTT and IVGTT was significantly lower than the values in rabbits with normal fasting IRI levels (fig. 2g, h, j-1). Similar results were observed in middle-aged rabbits (fig. 3). These results suggest that WHHLMI rabbits with high fasting IRI levels show insulin resistance.

\section{Correlation between Mesenteric Fat Accumulation and Other Parameters}

As shown in table 2, mesenteric fat was correlated to body size and accumulation of subcutaneous fat (axillary fat + inguinal fat) in adult and middle-aged WHHLMI rabbits. However, a significant correlation with aortic lesions was observed only in the adult rabbits. Subcutaneous fat accumulation did not correlate to aortic lesion area despite showing significant correlation to parameters of body size. As shown in table 3, mesenteric fat correlated to most blood chemical parameters but did not correlate to blood sugar and HDL triglyceride in middle-aged rabbits. These results may suggest that mesenteric fat accumulation affects insulin sensitivity or response, lipoprotein metabolism and atherosclerosis. However, a significant correlation with mesenteric fat accumulation in adult rabbits was observed only for fasting IRI, HOMA-IR and serum CRP levels. Although we analyzed rabbits aged 1115 months and 17-21 months, age did not correlate to mesenteric fat accumulation or any other parameter (data 

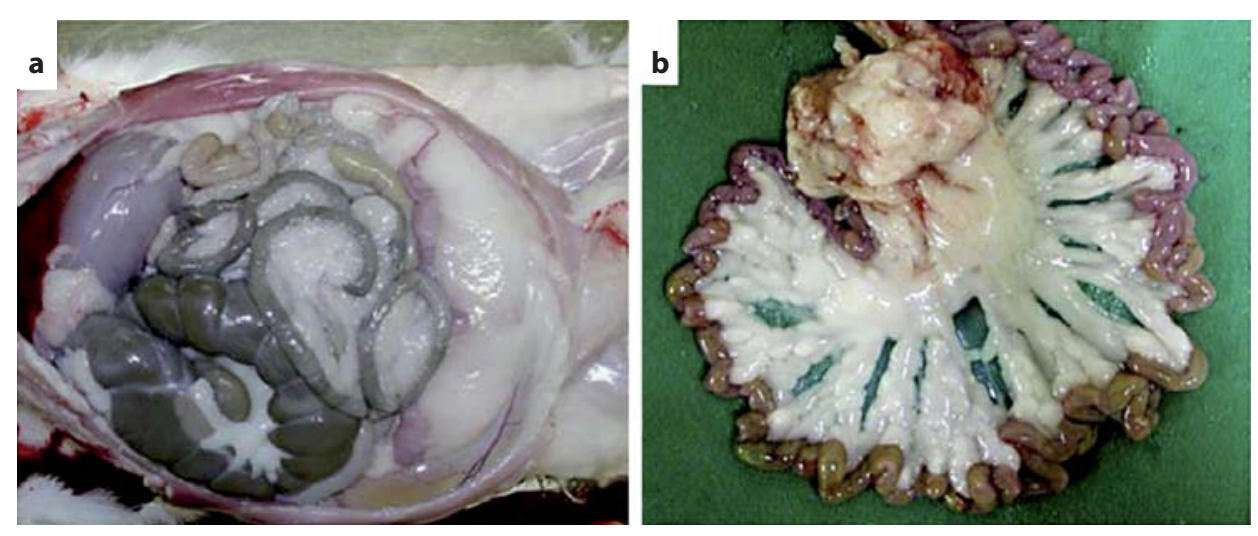

WHHLMI rabbit
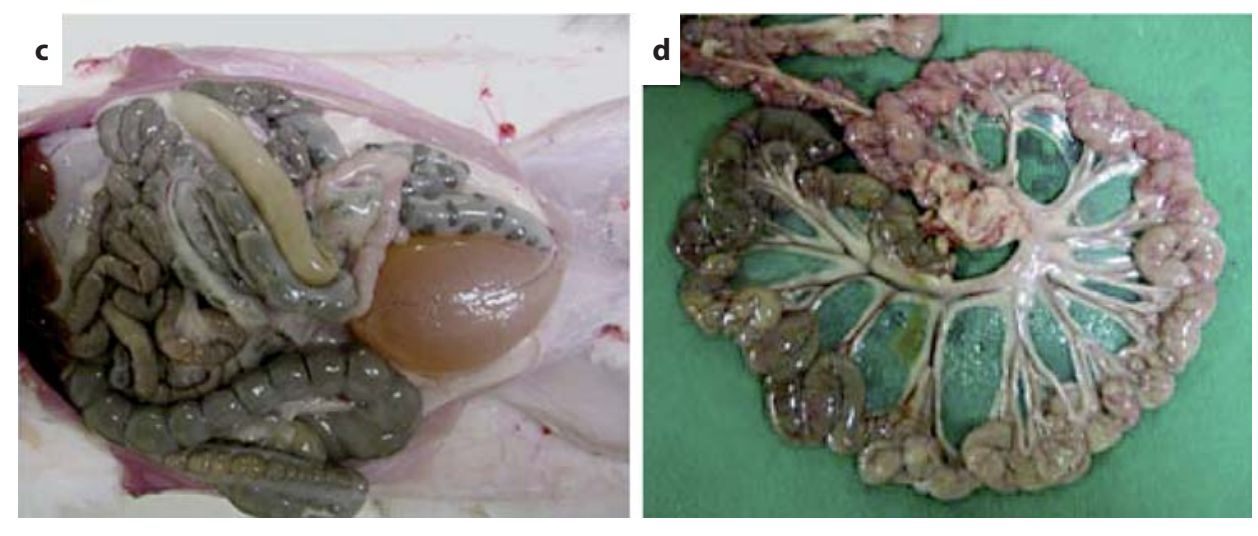

Japanese white rabbit

Fig. 1. Visceral fat accumulation in WHHLMI rabbits and immunohistochemical staining of mesenteric adipose tissue. $\mathbf{a}, \mathbf{b}$ Photographs of the accumulation of intraperitoneal fat and mesenteric fat in a WHHLMI rabbit (female, 18 months old). c, d Photographs of the accumulation of intraperitoneal fat and mesenteric fat in a Japanese white rabbit (male, 15 months old). e-h Photomicrographs of immunohistochemical staining of mesenteric adipose tissue of the WHHLMI rabbit.
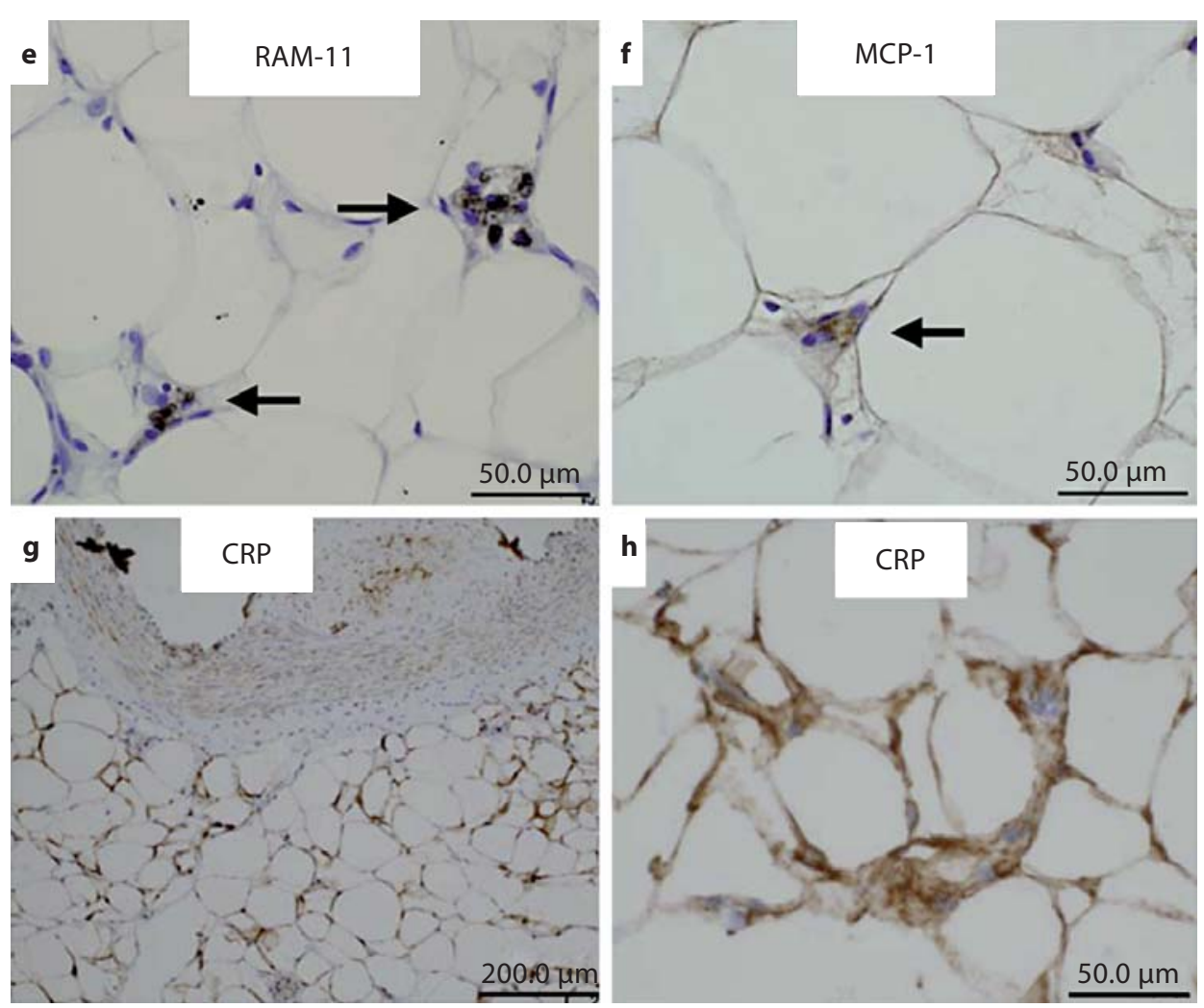
Fig. 2. Glucose tolerance tests in rabbits aged 10-15 months. a, b Blood sugar levels and serum IRI levels during the OGTT. c, d Blood sugar levels and serum IRI levels during the intravenous glucose tolerance test (IVGTT). e-h Results of the OGTT. i-I Results of the IVGTT. Data are presented as means \pm SEM. Statistical analyses were carried out with Scheffe's multiple comparison test. ${ }^{\mathrm{a}} \mathrm{p}<0.05$ compared with normal rabbits; ${ }^{b} \mathrm{p}<0.05$ compared with WHHLMI rabbits with low fasting IRI levels. $\mathrm{BS}=$ Blood sugar.
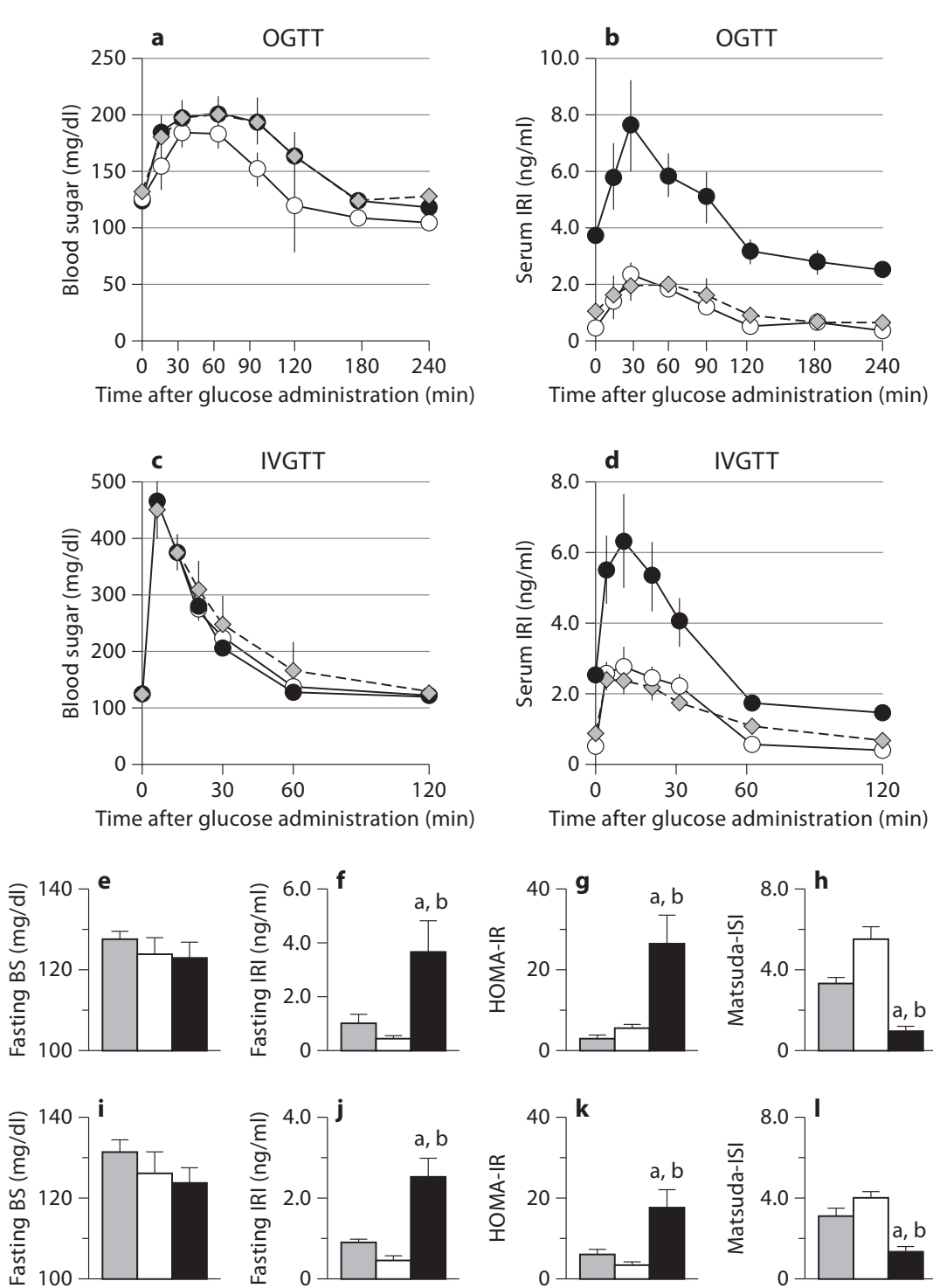

$\square$ Normal rabbits

$\square$ WHHLMI rabbits with fasting $\mid \mathrm{RI}<0.6 \mathrm{ng} / \mathrm{ml}$

WHHLMI rabbits with fasting IRI $>1.0 \mathrm{ng} / \mathrm{ml}$ not shown) in these age ranges. Therefore, the influence of age in these analyses was minor. Similar findings were observed in correlation analyses between subcutaneous fat and metabolic parameters, except serum CRP levels.

Correlation between the Index of Insulin Resistance in the OGTT or Fasting IRI Levels and Other Parameters

Fasting IRI levels correlated to body size, lipoprotein lipid levels and serum CRP levels in the middle-aged group but did not correlate to aortic atherosclerosis in the adult group (table 4). On the other hand, the Matsuda-ISI, an index of insulin sensitivity in the OGTT, showed a significant correlation to aortic atherosclerosis in adult WHHLMI rabbits $(\mathrm{r}=-0.477, \mathrm{p}=0.029)$ and the ratio of whole triglyceride level to HDL cholesterol $(\mathrm{r}=-0.549$, $\mathrm{p}=0.028)$ and serum CRP levels $(\mathrm{r}=-0.646, \mathrm{p}<0.001)$ in middle-aged WHHLMI rabbits. These results suggest that hyperinsulinemia and insulin resistance are independent in WHHLMI rabbits. 
Fig. 3. Glucose tolerance tests in WHHLMI rabbits aged 17-21 months. a, b Blood sugar levels and serum IRI levels during the OGTT. c, d Blood sugar levels and serum IRI levels during the intravenous glucose tolerance test (IVGTT). e-h Results of the OGTT. i-I Results of the IVGTT. Data are presented as means \pm SEM. Statistical analyses were carried out with Student's t test or Welch's t test. Statistical significance was set at $\mathrm{p}<0.05$. BS $=$ Blood sugar.
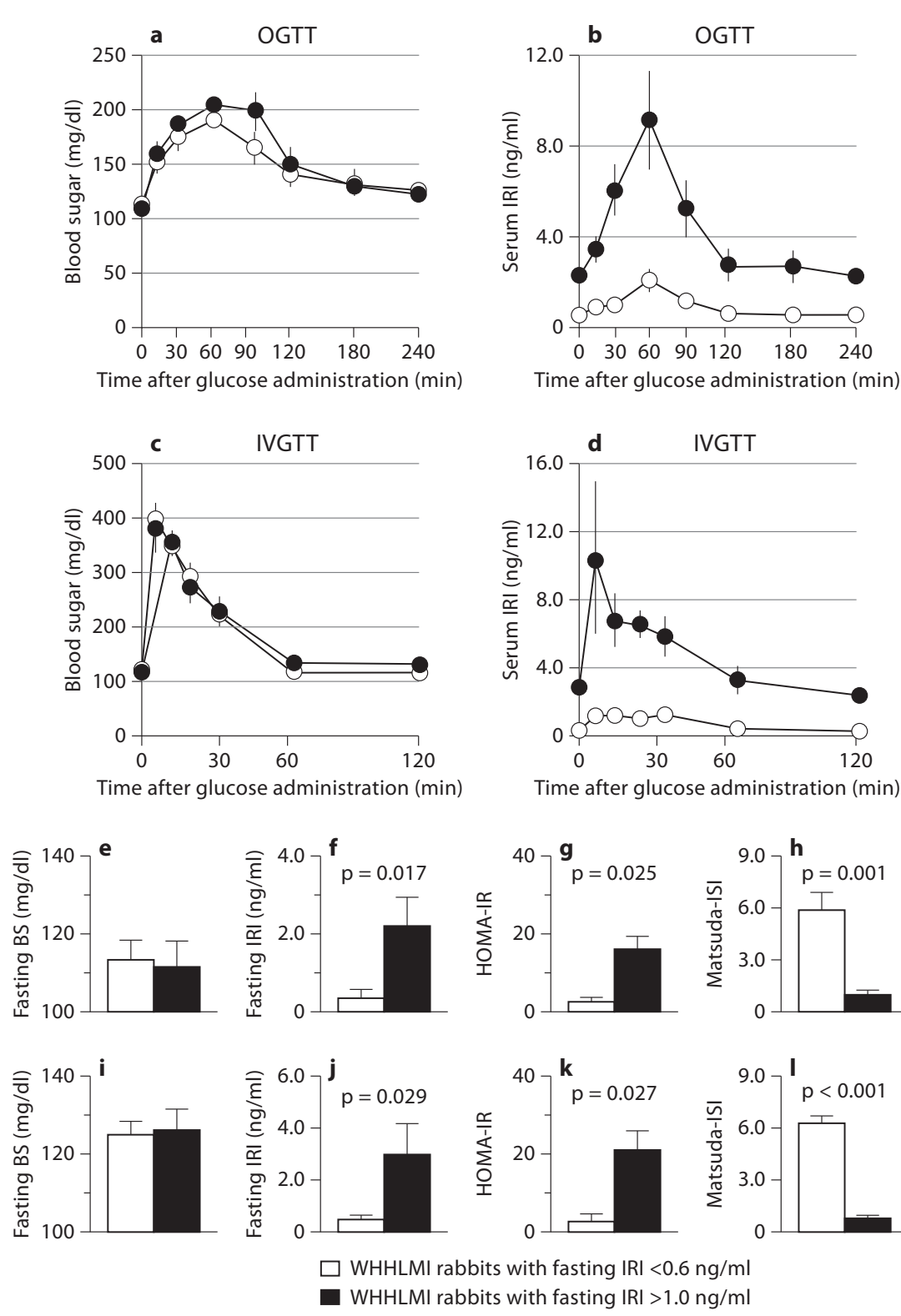

$\square$ WHHLMI rabbits with fasting IRI $<0.6 \mathrm{ng} / \mathrm{ml}$

WHHLMI rabbits with fasting $I R I>1.0 \mathrm{ng} / \mathrm{ml}$

\section{Discussion}

WHHLMI rabbits with high fasting IRI levels showed an accumulation of mesenteric fat and insulin resistance even with restricted feeding on normal chow. The mesenteric fat accumulation correlated to aortic atherosclerosis, body size, insulin sensitivity, lipoprotein metabolism and plasma CRP levels.

In WHHLMI rabbits, the accumulation of fat at the mesentery correlated with aortic lesion area in the adult group but not in the middle-aged group (table 2). This difference may be due to the extremely advanced atherosclerotic lesions in the middle-aged rabbits. Actually, the percentage area of lesions on the aortic surface was 75.1 $\pm 3.4 \%$ in the adult group and $88.2 \pm 0.8 \%$ in the middle-aged group (table 1). In the adult group, the percentage area of aortic lesions was $67.3 \pm 5.7 \%(\mathrm{n}=21)$ in rabbits with less than $60 \mathrm{~g}$ of mesenteric fat and $84.1 \pm 3.6 \%$ $(\mathrm{n}=15)$ in rabbits with more than $80 \mathrm{~g}$ of mesenteric fat $(p=0.018)$. The mean age was $13.2 \pm 0.3$ months in each 
Table 3. Correlation between accumulation of fat and biochemical parameters of adult (11- to 15-month-old) and middle-aged (17- to 21-month-old) WHHLMI rabbits

\begin{tabular}{|c|c|c|c|c|c|c|c|c|c|c|c|c|}
\hline & \multicolumn{6}{|c|}{ Adult rabbits } & \multicolumn{6}{|c|}{ Middle-aged rabbits } \\
\hline & \multicolumn{3}{|c|}{ mesenteric fat } & \multicolumn{3}{|c|}{ subcutaneous fat } & \multicolumn{3}{|c|}{ mesenteric fat } & \multicolumn{3}{|c|}{ subcutaneous fat } \\
\hline & $\mathrm{n}$ & $\mathrm{r}$ & $\mathrm{p}$ value & $\mathrm{n}$ & $\mathrm{r}$ & $\mathrm{p}$ value & $\mathrm{n}$ & $\mathrm{r}$ & $\mathrm{p}$ value & $\mathrm{n}$ & $\mathrm{r}$ & $\mathrm{p}$ value \\
\hline Fasting blood sugar & 21 & -0.162 & n.s. & 15 & 0.331 & n.s. & 37 & 0.352 & 0.033 & 32 & 0.206 & n.s. \\
\hline Fasting IRI & 21 & 0.520 & 0.016 & 15 & -0.197 & n.s. & 34 & 0.493 & 0.003 & 32 & 0.535 & 0.002 \\
\hline HOMA-IR & 21 & 0.479 & 0.028 & 15 & -0.160 & n.s. & 34 & 0.502 & 0.002 & 32 & 0.442 & 0.011 \\
\hline Matsuda-ISI on the IVGTT & 21 & -0.335 & n.s. & 15 & 0.1180 & n.s. & 17 & -0.570 & 0.018 & 15 & -0.353 & n.s. \\
\hline Matsuda-ISI on the OGTT & 21 & -0.307 & n.s. & 15 & 0.145 & n.s. & 17 & -0.570 & 0.017 & 15 & -0.646 & 0.009 \\
\hline \multicolumn{13}{|l|}{ Lipoprotein cholesterol } \\
\hline VLDL & 19 & -0.331 & n.s. & 16 & -0.184 & n.s. & 17 & 0.834 & $<0.001$ & 15 & 0.475 & 0.074 \\
\hline LDL & 19 & -0.032 & n.s. & 16 & 0.119 & n.s. & 17 & 0.570 & 0.021 & 15 & 0.689 & 0.005 \\
\hline HDL & 19 & -0.280 & n.s. & 16 & -0.219 & n.s. & 17 & -0.555 & 0.026 & 15 & -0.271 & n.s. \\
\hline Whole cholesterol & 19 & -0.110 & n.s. & 16 & -0.071 & n.s. & 17 & 0.701 & 0.002 & 15 & 0.667 & 0.007 \\
\hline \multicolumn{13}{|l|}{ Lipoprotein triglyceride } \\
\hline VLDL & 19 & 0.236 & n.s. & 16 & -0.134 & n.s. & 17 & 0.855 & $<0.001$ & 15 & 0.399 & n.s. \\
\hline LDL & 19 & 0.138 & n.s. & 16 & 0.025 & n.s. & 17 & 0.825 & $<0.001$ & 15 & 0.309 & n.s. \\
\hline HDL & 19 & 0.410 & n.s. & 16 & 0.625 & 0.010 & 17 & 0.066 & n.s. & 15 & 0.146 & n.s. \\
\hline Whole triglyceride & 19 & 0.233 & n.s. & 16 & 0.020 & n.s. & 17 & 0.836 & $<0.001$ & 15 & 0.367 & n.s. \\
\hline \multicolumn{13}{|l|}{ Whole triglyceride/HDL } \\
\hline cholesterol ratio & 19 & 0.268 & n.s. & 16 & 0.187 & n.s. & 17 & 0.781 & $<0.001$ & 15 & 0.238 & n.s. \\
\hline Serum CRP & 20 & 0.455 & 0.044 & 17 & 0.211 & n.s. & 17 & 0.601 & 0.023 & 12 & 0.139 & n.s. \\
\hline
\end{tabular}

Subcutaneous fat was measured as the sum of inguinal fat and axillary fat. Correlation analyses were carried out with Pearson's correlation test. A value of $\mathrm{p}<0.05$ was considered statistically significant. IVGTT = Intravenous glucose tolerance test; OGTT = oral glucose tolerance test; VLDL = very low-density lipoprotein; LDL = low-density lipoprotein; HDL = high-density lipoprotein; $\mathrm{CRP}=$ C-reactive protein; n.s. = not significant.

Table 4. Correlation between fasting IRI and physical or biochemical parameters in WHHLMI rabbits

\begin{tabular}{|c|c|c|c|c|c|c|}
\hline & \multicolumn{3}{|c|}{ Adult rabbits } & \multicolumn{3}{|c|}{ Middle-aged rabbits } \\
\hline & $\mathrm{n}$ & $\mathrm{r}$ & $\mathrm{p}$ value & $\mathrm{n}$ & $\mathrm{r}$ & $\mathrm{p}$ value \\
\hline Body weight & 21 & 0.133 & n.s. & 18 & 0.488 & 0.047 \\
\hline Abdominal circumference & 21 & 0.190 & n.s. & 18 & 0.389 & n.s. \\
\hline Body mass index & 21 & -0.192 & n.s. & 16 & 0.403 & 0.012 \\
\hline \multicolumn{7}{|l|}{ Lipoprotein cholesterol } \\
\hline VLDL & 18 & -0.287 & n.s. & 16 & 0.552 & 0.027 \\
\hline LDL & 18 & -0.234 & n.s. & 16 & 0.658 & 0.006 \\
\hline HDL & 18 & -0.158 & n.s. & 16 & -0.416 & n.s. \\
\hline \multicolumn{7}{|l|}{ Lipoprotein triglyceride } \\
\hline VLDL & 18 & 0.454 & n.s. & 16 & 0.818 & 0.005 \\
\hline LDL & 18 & 0.324 & n.s. & 16 & 0.690 & $<0.001$ \\
\hline HDL & 18 & -0.125 & n.s. & 16 & 0.054 & n.s. \\
\hline Whole triglyceride/HDL cholesterol ratio & 18 & 0.303 & 0.22 & 16 & 0.719 & 0.002 \\
\hline \multicolumn{7}{|l|}{ Blood pressure } \\
\hline Systolic & 15 & 0.218 & n.s. & 14 & 0.109 & n.s. \\
\hline Diastolic & 15 & -0.315 & n.s. & 14 & 0.002 & n.s. \\
\hline Average & 15 & -0.320 & n.s. & 14 & 0.030 & n.s. \\
\hline Aortic lesion area & 21 & 0.326 & n.s. & 18 & -0.184 & n.s. \\
\hline Serum CRP & 19 & 0.0912 & n.s. & 16 & 0.825 & $<0.001$ \\
\hline
\end{tabular}

Correlation analyses were carried out with Pearson's correlation test. A value of $\mathrm{p}<0.05$ was considered statistically significant.

$\mathrm{VLDL}=$ Very low-density lipoprotein; $\mathrm{LDL}=$ low-density lipoprotein; $\mathrm{HDL}=$ high-density lipoprotein; $\mathrm{CRP}=\mathrm{C}$-reactive protein; n.s. = not significant. 
group. These results strongly suggest that mesenteric fat accelerates the progression of aortic atherosclerosis in adult rabbits. Previous studies suggested that adipocytokines derived from mesenteric fat can affect dyslipidemia, glucose metabolism, hypertension, inflammation and thrombogenesis [23]. These secondary disorders are related to atherogenesis $[5,10,23]$. Although several studies demonstrated that a high-fat diet induced obesity, insulin resistance, intraperitoneal fat accumulation and slight atherosclerosis $[8-10,14]$, there are no studies on the correlation between mesenteric fat accumulation and atherosclerosis. In addition, Matsuzawa [24] pointed out that mesenteric fat has an important influence on dyslipidemia and atherogenesis because it supplies free fatty acids to the liver through the portal veins. Since atherosclerotic lesions enlarged to cover most of the aortic surface due to hypercholesterolemia in middle-aged rabbits, the influence of mesenteric fat accumulation might be small. In adult rabbits, the Matsuda-ISI of the OGTT correlated negatively to aortic lesions but fasting IRI levels did not. These results indicate that insulin resistance affects the progression of atherosclerosis. Although we cannot explain the present results, insulin resistance may accelerate atherosclerosis through adipocytokines secreted from adipocytes of mesenteric fat [5].

In WHHLMI rabbits, mesenteric fat accumulation correlated to the Matsuda-ISI, HOMA-IR and fasting IRI levels as in other animal models reported previously [25]. Although Matsuda-ISI values of adult rabbits did not correlate with mesenteric fat accumulation, those of middleaged rabbits showed a significant correlation. The weight of mesenteric fat was $69.8 \pm 4.6 \mathrm{~g}(\mathrm{n}=46)$ in adult rabbits and $92.2 \pm 6.5 \mathrm{~g}(\mathrm{n}=52)$ in middle-aged rabbits $(\mathrm{p}=$ $0.006)$. These results suggest that insulin resistance of WHHLMI rabbits developed with an increase in mesenteric fat accumulation. In addition, our previous study demonstrated that metabolic syndrome-like symptoms in WHHL rabbits with high fasting IRI levels were ameliorated by the administration of troglitazone, a thiazolidinedione derivative [18]. These results suggest that WHHLMI rabbits with mesenteric fat accumulation correspond to human metabolic syndrome.

In middle-aged WHHLMI rabbits, mesenteric fat correlated positively to apolipoprotein B-containing lipoprotein lipid levels and negatively to HDL cholesterol levels. The mechanisms of the development of dyslipidemia in patients with metabolic syndrome or obesity were summarized previously [26]. The ratio of plasma triglyceride to HDL cholesterol showed a high correlation similar to that in obese individuals showing insulin resistance
$[27,28]$. It is well known that HDL cholesterol negatively correlates to cardiovascular diseases. In mice, HDL cholesterol levels were increased by a high-fat diet $[29,30]$ or increased or unchanged by obesity $[31,32]$. An increase in HDL cholesterol levels was also observed in rat $[33,34]$ and swine [10] models. However, HDL cholesterol levels were decreased in normal rabbits fed a high-fat diet, and overexpression of lipoprotein lipase improved insulin resistance in rabbits fed a high-fat diet [35-37]. These differences in changes in HDL cholesterol levels may be due to species differences [12]. The results of previous studies suggest that rabbit models for metabolic syndrome or insulin resistance have the advantage of both an increase in triglyceride levels and a decrease in HDL cholesterol levels due to the progression of mesenteric fat accumulation.

In the present study, plasma CRP levels correlated to mesenteric fat accumulation in both adult and middleaged WHHLMI rabbits and to the Matsuda-ISI and fasting serum IRI levels in middle-aged rabbits. In mesenteric fat, CRP and MCP-1 were positive and macrophages had infiltrated, suggesting inflammation. On the other hand, serum CRP levels did not correlate to aortic atherosclerosis. These results suggest that serum CRP levels in WHHLMI rabbits affected the progression of metabolic syndrome or insulin resistance. Similar findings were observed in patients with metabolic syndrome [38]. In rabbits fed a high-fat diet, serum CRP levels increased, accompanying insulin resistance and with an increase in intraperitoneal fat accumulation [14]. In rodents, CRP was not detected in the circulation, and the inflammatory marker in that species is serum amyloid P component rather than CRP as in humans and rabbits [39]. These findings suggest the advantage of a rabbit model for metabolic syndrome.

In conclusion, since the characteristics of WHHLMI rabbits with large amounts of mesenteric fat resemble those of human metabolic syndrome even with restricted feeding of normal chow, the accumulation of visceral fat and insulin resistance in WHHLMI rabbits may be controlled by genetic factors. WHHLMI rabbits with mesenteric fat accumulation may be a new animal model for human metabolic syndrome.

\section{Acknowledgement}

This work was supported in part by grants-in-aid for scientific research from the Ministry of Education, Culture, Sports and Technology, Japan (20500373 and 23300157). 


\section{References}

-1 Delahoy PJ, Magliano DJ, Webb K, Grobler $\mathrm{M}$, Liew D: The relationship between reduction in low-density lipoprotein cholesterol by statins and reduction in risk of cardiovascular outcomes: an updated meta-analysis. Clin Ther 2009;31:236-244.

-2 DeFronzo RA, Abdul-Ghani M: Assessment and treatment of cardiovascular risk in prediabetes: impaired glucose tolerance and impaired fasting glucose. Am J Cardiol 2011; 108:3B-24B.

$\checkmark 3$ Pais R, Silaghi H, Silaghi AC, Rusu ML, Dumitrascu DL: Metabolic syndrome and risk of subsequent colorectal cancer. World J Gastroenterol 2009;15:5141-5148.

$\checkmark 4$ Alberti KG, Zimmet P, Shaw J; IDF Epidemiology Task Force Consensus Group: The metabolic syndrome - a new worldwide definition. Lancet 2005;366:1059-1062.

$\checkmark 5$ Matsuzawa Y, Funahashi T, Kihara S, Shimomura I: Adiponectin and metabolic syndrome. Arterioscler Thromb Vasc Biol 2004; 24:26-33.

$\checkmark 6$ Manolagas SC, Almeida M: Gone with the Wnts: beta-catenin, T-cell factor, forkhead box $\mathrm{O}$, and oxidative stress in age-dependent diseases of bone, lipid, and glucose metabolism. Mol Endocrinol 2007;21:2605-2614.

$>7$ Bergen WG, Mersmann HJ: Comparative aspects of lipid metabolism: impact on contemporary research and use of animal models. J Nutr 2005;135:2499-2502.

$>8$ King VL, Hatch N, Chan HW, de Beer MC, de Beer FC, Tannock LR: A murine model of obesity with accelerated atherosclerosis. Obesity 2010;18:35-41.

9 Ribas V, Drew BG, Le JA, Soleymani T, Daraei $\mathrm{P}$, Sitz D, Mohammad L, Henstridge DC, Febbratio MN, Hewitt SC, Korach KS, Bensinger SJ: Myeloid-specific estrogen receptor $\alpha$ deficiency impairs metabolic homeostasis and accelerates atherosclerotic lesion development. Proc Natl Acad Sci USA 2011;108: 16457-16462.

10 Neeb ZP, Edwards JM, Alloosh M, Long X, Mokelke EA, Sturek M: Metabolic syndrome and coronary artery disease in Ossabaw compared with Yucatan swine. Comp Med 2010;60:300-315.

-11 Shiomi M, Fun J: Unstable coronary plaques and cardiac events in myocardial infarctionprone Watanabe heritable hyperlipidemic rabbits: questions and quandaries. Curr Opin Lipidol 2008;19:631-636.

12 Shiomi M, Ito T: The Watanabe heritable hyperlipidemic (WHHL) rabbit, its characteristics and history of development: a tribute to the late Dr. Yoshio Watanabe. Atherosclerosis 2009;207:1-7.

- 13 Kawai T, Ito T, Ohwada K, Mera Y, Matsushita M, Tomoike H: Hereditary postprandial hypertriglyceridemic rabbit exhibits insulin resistance and central obesity: a novel model of metabolic syndrome. Arterioscler Thromb Vasc Biol 2006;26:2752-2757.

- 14 Waqar AB, Koike T, Yu Y, Inoue T, Aoki T, Liu E, Fan J: High-fat diet without excess calories induces metabolic disorders and en- hances atherosclerosis in rabbits. Atherosclerosis 2010;213:148-155.

15 Watanabe Y: Serial inbreeding of rabbits with hereditary hyperlipidemia (WHHLrabbit). Atherosclerosis 1980;118:81-84.

16 Shiomi M, Ito T, Yamada S, Kawashima S, Fan J: Development of an animal model for spontaneous myocardial infarction (WHHLMI rabbit). Arterioscler Thromb Vasc Biol 2003;23:1239-1244.

17 Zhang B, Saku K, Hirata K, Liu R, Tateishi K, Shiomi M, Arakawa K: Quantitative characterization of insulin-glucose response in Watanabe heritable hyperlipidemic and cholesterol-fed rabbits and the effect of cilazapril. Metabolism 1994;43:360-366.

18 Shiomi M, Ito T, Tsukada T, Tsujita Y, Horikoshi $\mathrm{H}$ : Combination treatment with troglitazone, an insulin action enhancer, and pravastatin, an inhibitor of HMG-CoA reductase, shows a synergistic effect on atherosclerosis of WHHL rabbits. Atherosclerosis 1999;142:345-353.

19 Matthews DR, Hosker JP, Rudenski AS, Naylor BA, Treacher DF, Turner RC: Homeostasis model assessment: insulin resistance and beta-cell function from fasting plasma glucose and insulin concentrations in man. Diabetologia 1985;28:412-419.

-20 Matsuda M, DeFronzo RA: Insulin sensitivity indices obtained from oral glucose tolerance testing. Diabetes Care 1999;22:1462-1470.

21 Shiomi M, Ito T, Watanabe Y, Tsujita Y, Kuroda M, Arai M, Fukami M, Fukushige J, Tamura A: Suppression of established atherosclerosis and xanthomas in mature WHHL rabbits by keeping their serum cholesterol levels extremely low: effect of pravastatin sodium in combination with cholestyramine. Atherosclerosis 1990;83:69-80

22 Shiomi M, Yamada S, Amano Y, Nishimoto T, Ito T: Lapaquistat acetate, a squalene synthesis inhibitor, changes macrophage/lipidrich coronary plaques of hypercholesterolemic rabbits into fibrous lesions. Br J Pharmacol 2008;154:949-957.

23 Matsuzawa Y: Adipocytokines and metabolic syndrome. Semin Vasc Med 2005;5:34-39.

24 Matsuzawa Y: Pathophysiology and molecular mechanisms of visceral fat syndrome: the Japanese experience. Diabetes Metab Rev 1997; 13:3-13.

25 Panchal SK, Brown L: Rodent models for metabolic syndrome research. J Biomed Biotech 2011;2011:1-14.

26 Chan DC, Barrett HP, Watts GF: Dyslipidemia in visceral obesity: mechanisms, implications, and therapy. Am J Cardiovasc Drugs 2004;4:227-246.

27 Karelis AD, Pasternyk SM, Messier L, StPierre DH, Lavoie JM, Garrel D, RabasaLhoret R: Relationship between insulin sensitivity and the triglyceride-HDL-C ratio in overweight and obese postmenopausal women: a MONET study. Appl Physiol Nutr Metab 2007;32:1089-1096.
28 Brehm A, Pfeiler G, Pacini G, Vierhapper H, Roden M: Relationship between serum lipoprotein ratios and insulin resistance in obesity. Clin Chem 2004;50:2316-2322.

29 Colloson KS, Maqbool ZM, Inglis AL, Makhoul NJ, Saleh SM, Bakheet RH, Al-Johi MA, Al-Rabiaj RK, Zaidi MZ, Al-Mohanna FA: Effect of dietary monosodium glutamate on HFCS-induced hepatic steatosis: expression profiles in the liver and visceral fat. Obesity (Silver Spring) 2010;18:1122-1134.

30 Hahn BH, Lourencço EV, McMahon M, Skaggs B, Le E, Anderson M, Iikuni N, Lai CK, LaCava A: Pro-inflammatory high-density lipoproteins and atherosclerosis are induced in lupus-prone mice by a high-fat diet and leptin. Lupus 2010;19:913-917.

31 Suzuki M, Kakuta H, Takahashi A, Shimano H, Tada-Iida K, Yokoo T, Kihara R, Yamada $\mathrm{N}$ : Effects of atorvastatin on glucose metabolism and insulin resistance in KK/Ay mice. J Atheroscler Thromb 2005; 12:77-84.

32 Silver DL, Jiang XC, Tall AR: Increased high density lipoprotein (HDL), defective hepatic catabolism of Apo-A1 and Apo-AII, and decreased Apo-AI mRNA in ob/ob mice. Possible role of leptin in stimulation of HDL turnover. J Biol Chem 1999;274:4140-4146.

-33 Hikita M, Bujo H, Yamazaki K, Taira K, Takahashi K, Kobayashi J, Saito Y: Differential expression of lipoprotein lipase in tissues of the rat model with visceral obesity and postprandial hyperlipidemia. Biochem Biophys Res Commun 2000;277:423-429.

34 Elam MB, von Wronski MA, Cagen L, Thorngate F, Kumar P, Heimberg HG: Lipoprotein alterations in 10 - and 20 -week-old Zucker diabetic fatty rats: hyperinsulinemic versus insulinopenic hyperglycemia. Metabolism 1998;47:1315-1324

35 Kitajima S, Morimoto M, Liu E, Koike T, Higaki Y, Taura Y, Mamba K, Itamoto K, Watanabe T, Tsutsumi K, Yamada N, Fan J: Overexpression of lipoprotein lipase improves insulin resistance induced by a highfat diet in transgenic rabbits. Diabetologia 2004;47:1202-1209.

>36 Koike T, Liang J, Wang X, Ichikawa T, Shiomi M, Liu G, Sun H, Kitajima S, Morimoto M, Watanabe T, Yamada N, Fan J: Overexpression of lipoprotein lipase in transgenic Watanabe heritable hyperlipidemic rabbits improves hyperlipidemia and obesity. J Biol Chem 2004;279:7521-7529.

>37 Liu E, Kitajima S, Higaki Y, Morimoto M, Sun H, Watanabe T, Yamada N, Fan J: High lipoprotein activity increases insulin sensitivity in transgenic rabbits. Metabolism 2005;54:132-138.

38 Devarj S, Singh U, Jialal I: Human C-reactive protein and the metabolic syndrome. Curr Opin Lipidol 2009;20:182-189.

$>39$ Pepys MB, Baltz M, Gomer K, Davies AJ, Doenhoff M: Serum amyloid P-component is an acute-phase reaction in the mouse. $\mathrm{Na}$ ture 1979;278:259-261. 